\title{
CONSIDERACIONES EN TORNO AL DELITO DE CLONACIÓN*
}

\section{CONSIDERATIONS ON THE CRIME OF CLONING}

\author{
Iñigo de Miguel Beriain ${ }^{1}$ \\ Universidad del País Vasco (UPV/EHU) \\ Emilio José Armaza Armaza ${ }^{2}$ \\ Universidad del País Vasco (UPV/EHU)
}

\begin{abstract}
Resumen:
En el presente trabajo se analizan algunos problemas interpretativos que giran en torno al delito de clonación previsto en el artículo 161.2 del CP español. Se examina, críticamente, su escasa consistencia y la ambigüedad de su literalidad, ofreciendo, a cambio, alguna sugerencia de mejora. Por otra parte, se analizan, también críticamente, las dos principales propuestas doctrinales en relación con la identificación del bien jurídico tutelado y se ofrecen nuevas propuestas con el fin de alentar el debate y, con ello, el progreso del saber penal.
\end{abstract}

\section{Palabras clave:}

Clonación, Delito, Bien jurídico, Integridad genética, Identidad genética, Supervivencia de la especie humana.

\begin{abstract}
:
This paper analyzes some of the interpretative problems surrounding the crime of cloning (Article 161.2 of the Spanish Criminal Code). It critically examines its lack of consistency and the ambiguity of its wording, offering, in return, some suggestions for improvement. The two main doctrinal proposals regarding the identification of the legally protected interest are, also, critically analyzed, and new proposals are offered with the aim of encouraging debate and, thus, the progress of Criminal Law.
\end{abstract}

Keywords:

Cloning, Crime, Legally protected interest, Genetic Integrity, Genetic Identity, Survival of the human species.

\section{INTRODUCCIÓN}

A lo largo de los últimos años, hemos asistido atónitos a la consecución de una serie de descubrimientos científicos que han cambiado radicalmente las circunstancias en las que han de desenvolverse ciencias como la medicina, la biología, o la genética. La aparición de una circunstancia como la clonación celular, o el logro de hitos del calibre de la elaboración del primer mapa del Genoma Humano, o el desarrollo de técnicas tan prometedoras como las que hacen posible las terapias génicas han modificado sustancialmente muchas de nuestras ideas

\footnotetext{
* El presente trabajo ha sido elaborado en el marco de las ayudas del Departamento de Educación, Universidades e Investigación del Gobierno Vasco para apoyar las actividades de Grupos de Investigación del Sistema Universitario Vasco (Grupo de Investigación Cátedra de Derecho y Genoma Humano con Ref. IT1066-16 y Grupo de Investigación COMERCIO: Constitución, mercados e integración con Ref. IT1386-19). Asimismo, se elabora en el marco del Programa Estatal de Promoción del Talento y su Empleabilidad, en el marco del Plan Estatal de Investigación Científica y Técnica y de Innovación 2013-2016 —Ayuda Ramón y Cajal con Referencia RYC2016-20708.

${ }^{1}$ Ikerbasque Research Professor - Investigador del G.I. Cátedra de Derecho y Genoma Humano - Universidad del País Vasco UPV/EHU (Bilbao, España). Orcid: https://orcid.org/0000-0002-2650-5280

${ }^{2}$ Investigador “Ramón y Cajal” y Profesor de Derecho Penal - Universidad de Deusto - Investigador Colaborador del G.I. Cátedra de Derecho y Genoma Humano - Universidad del País Vasco UPV/EHU (Bilbao, España). Orcid: https://orcid.org/0000-0002-8816-9606
} 
acerca de lo que es posible y lo que no lo es, siendo así que cada día resulta más complicado distinguir la realidad de la ciencia-ficción.

Esta revolución científica ha generado nuevos y sorprendentes escenarios para la vida humana, siendo así que no es exagerado, a nuestro juicio, decir que el hombre se halla, a principios del siglo XXI, en una situación decididamente compleja. De un lado, las enormes posibilidades que se abren ante nuestros ojos son motivo de alegría y optimismo. De otro, surge inevitable la inquietud hacia los posibles desastres a los que podría abocarnos una mala interpretación de los valores en juego o, simplemente, un uso inadecuado de estos nuevos conocimientos y de las tecnologías que surgen a su sombra ${ }^{3}$. La conciencia de esta situación ha llevado, inevitablemente, al nacimiento de dos nuevos saberes, la Bioética y el Bioderecho, que podrían definirse como las ramas de la Ética o del Derecho que se ocupan de las ciencias de la vida ${ }^{4}$.

Junto a ellos, no obstante, se situará siempre el Derecho Penal, en su posición de herramienta de particular importancia en la defensa de los bienes jurídicos fundamentales, una vocación desde la que no puede asistir impertérrito a la aparición de unas tecnologías que son magníficas oportunidades, pero también pueden constituir serias amenazas para el ser humano. De ahí que la mayoría de los códigos penales actuales incluyan referencias explícitas a los delitos de manipulaciones genéticas o de clonación. De hecho, nuestro texto empezará por

\footnotetext{
${ }^{3}$ Preocupación, en cualquier caso, plenamente justificada, por cuanto, como muy bien ha descrito el profesor ROMEO CASABONA, "más que ninguna otra rama del saber, las Ciencias Biomédicas comportan una incidencia directa sobre el ser humano en todo su proceso vital y en su propia identidad colectiva” (Cfr. RoMEO CASABONA, C. M., “La relación entre la Bioética y el Derecho”, en Romeo CASABOnA, C. M. (Coord.), Derecho Biomédico y Bioética, Comares, Colección Biblioteca Comares de Derecho y Ciencias de la Vida, nº 1, Granada, 1998, pág. 162). En el mismo sentido, Lydia FEITo ha señalado que "la magnitud de los poderes que ostenta la biomedicina y, en general, la ciencia y la técnica actuales, es enorme en comparación con épocas pasadas. Tales logros han permitido a la humanidad situarse en una posición de dominio del entorno natural que supera con creces los pronósticos más optimistas que cualquier hombre o mujer del pasado hubiera podido concebir. Sin embargo, también son gigantescas las responsabilidades adquiridas con tales poderes. También es este uno de los puntos álgidos en la historia de la humanidad en cuanto a necesidad de reflexión ética se refiere. La preocupación fundamental reside en la necesidad imperiosa de impedir que se abra, o se agrande, una sima entre la ciencia y la ética” (Cfr. FEITO GRANDE, L., "Poner en marcha la ética: elementos básicos para el análisis de la terapia génica humana”, en Revista de Derecho y Genoma Humano, n 4, 1996, pág. 141 y 142).

${ }^{4}$ La idea misma de si la Bioética es o no una rama de la Ética general ha suscitado cierta polémica. Aquí, no obstante, nos mostraremos de acuerdo con esa hipótesis, haciéndonos así eco de las palabras del profesor ROMEO CASABONA cuando escribe que "la Bioética no suele ser entendida como una disciplina especial, sino especializada, dentro de la Ética general (de la cual se nutre en buena parte de sus fundamentos, y a la inversa, desarrolla aquélla), no tanto como Ética teórica como cuanto aplicada” (Cfr. RomeO CASABONA, C. M., "La relación entre la Bioética y el Derecho”, en ROMEO CASABONA, C. M. (Coord.), Derecho Biomédico y Bioética, cit., págs. 153 y 154). Véase también: MinetTi, J. A. y M. J. BerTOMEU, "La fundamentación de la ética biomédica”, en Jano, nº 649, 1985, pág. 50. En este mismo sentido, ROMEO CASABONA señala que el Bioderecho ha de ser entendido como el "conjunto de materias jurídicas relacionadas con todos los seres vivos en general, abarcando toda la materia viva presente en el planeta, es decir, animales y plantas, y en particular el ser humano, sus ecosistemas y su evolución” (Cfr. Romeo CASABOnA, C. M., “Bioderecho y Bioética”, en RomeO CASABOnA, C. M. (Dir.), Enciclopedia de Bioderecho y Bioética, Tomo I, Comares, Granada, 2011, pág. 188.
} 
ilustrar el ejemplo del Código Penal español. Por desgracia, tendremos que criticar seriamente la escasa consistencia y la ambigüedad de su literalidad, ofreciendo, a cambio, alguna sugerencia de mejora.

No obstante, nuestro análisis se centrará especialmente en el concepto de bien jurídico protegido, que resulta fundamental en cualquier caracterización del delito. Llegados a ese punto, intentaremos tanto mostrar las principales tendencias doctrinales en este sentido, como las razones por las que disentimos de la opinión expresada por la mayor parte ellos. En compensación, intentaremos ofrecer nuevas y, esperamos, estimulantes propuestas, que sirvan para superar el marco jurídico actual. Por último, terminaremos con algunas conclusiones y observaciones finales que permitan sintetizar todo lo expuesto en el presente texto. Esperemos que sean útiles para salvar los obstáculos que ahora mismo encontramos en nuestros marcos normativos.

\section{LA REGULACIÓN DEL DELITO DE CLONACIÓN EN EL CÓDIGO PENAL ESPAÑOL}

Como acabamos de anunciar, la primera parte de este texto irá enfocado a analizar la forma en que se ha querido normativizar el delito de clonación. Para ello recurriremos al ejemplo de España, que nos resulta particularmente familiar, y que además resulta muy útil por las disfunciones que presenta. Permítasenos, por tanto, citar aquí el artículo 161 del Código Penal vigente, que señala, a este respecto, literalmente lo siguiente:

\footnotetext{
Artículo 161

1. Serán castigados con pena de prisión de uno a cinco años e inhabilitación especial para empleo o cargo público, profesión u oficio de seis a diez años quienes fecunden óvulos humanos con cualquier fin distinto a la procreación humana.

2. Con la misma pena se castigará la creación de seres humanos idénticos por clonación u otros procedimientos dirigidos a la selección de razas.
}

Su redacción, como cabe apreciar, es sumamente farragosa, lo que hace que la interpretación, siempre necesaria en un texto, aunque haya quien todavía defienda otros postulados (más bien decimonónicos) sea, en esta ocasión, particularmente exigente. Pues bien, intentando desentrañar qué se dice ahí de las conductas clonatorias, conviene empezar señalando que, desde luego, el primer número del artículo citado no se refiere a la clonación, por cuanto el mero hecho de que exista un fecundación lo excluye. En cuanto al segundo punto, llama poderosamente la atención que se hable de creación de seres humanos idénticos ¿por 
clonación? Esta construcción nos lleva a la conclusión de que la técnica legislativa utilizada para criminalizar este delito no puede, sino, ser calificada de absurda. En efecto, el legislador señala que la finalidad del autor del delito (“creación de seres humanos idénticos”) se ha de alcanzar con el uso de un medio muy específico (“por clonación”) y que, en puridad, no es un medio comisivo sino, también, la propia finalidad perseguida por el autor (el legislador, por tanto, identifica una técnica con la finalidad que persigue) ${ }^{5}$. Crear seres humanos idénticos es clonar seres humanos, con las salvaguardas que introduciremos después. Por tanto, no tiene sentido introducir una fórmula que, de tomarnos en serio, vendría a decir que "se castigará la clonación por clonación u otros procedimientos dirigidos a la selección de razas”.

La única interpretación razonable de la inclusión de esa extraña coletilla (“por clonación”) sería deducir que lo que el legislador deseaba decir (pensamos, aunque resulta difícil adivinarlo) era algo así como que se penalizará la creación de seres humanos genéticamente (curiosamente, esta palabra, esencial, no figura en el texto) idénticos mediante transferencia nuclear. Saber si, además, el autor de esta tropelía tenía en mente la prohibición de la otra forma de clonar un ser humano, esto es, la división del embrión o gemelación artificial, esto es, la partición en laboratorio de un embrión en sus primeras fases de desarrollo, resulta mucho más complejo ${ }^{6}$, por cuanto la frase “otros procedimientos dirigidos a la selección de razas” es un auténtico enigma, al menos para nuestro torpe entendimiento ${ }^{7}$. ROMEO MALANDA, por ejemplo, considera que la inclusión de la paráfrasis citada avala esta hipótesis, cosa que, de otro lado, sería coherente con lo dispuesto en el Convenio de Oviedo.

\footnotetext{
${ }^{5}$ La errática técnica legislativa utilizada, quizás ha incluso condicionado las construcciones conceptuales de una parte de la doctrina española, llevándola, en cierta medida, a reflejar esta cuestionable caracterización del delito de clonación. Así, según QuERALT JiMÉNEZ, “la clonación es la técnica de reproducción artificial en cuya virtud se obtiene de una célula o conjunto de células de un sujeto otro idéntico, sin mediar fecundación de ningún tipo. Clonar es, en definitiva, copiar, pero no reproducir. De esta suerte, encontrados un sujeto o sujetos satisfactorios — ¿para quién?-, se podría obtener dobles que tanto podrían convertirse en los amos del universo como en esclavos de los que lo fueran o se tuvieran por tales” (Queralt Jiménez., J. J., Derecho Penal Español. Parte Especial, José María Bosch Editor, S. L., Barcelona, 1996, pág. 54). Obviamente, el autor identifica la técnica transferencia de núcleos celulares con la finalidad de clonar un ser humano.

${ }^{6}$ Véanse al respecto las siguientes referencias: RomeO CASABOnA, C. M., "Los delitos relativos a la manipulación genética”, cit., pág. 359; RoMEO MALANDA, S., Intervenciones genéticas sobre el ser humano y Derecho Penal, Cátedra Interuniversitaria de Derecho y Genoma Humano - Editorial Comares, Granada, 2007, pág. 366 y ss.; DE La Cuesta Arzamendi, "Los llamados delitos de manipulación genética en el nuevo Código Penal español de 1995”, en Revista de Derecho y Genoma Humano, nº 5, 1996, pág. 70.

${ }^{7}$ Véase, al respecto, REy Del CASTILLO, J., "La situación de la clonación humana en el ámbito internacional”, en Revista de Derecho y Genoma Humano / Law and the Human Genome Review, Núm. 24, pág. 188. De hecho, y como ha puesto de manifiesto RoMEO MALANDA, la redacción del Código Penal permite preguntarse, en primer lugar, si nos hallamos ante un único tipo delictivo o si, por el contrario, son dos (Cfr. ROMEO MALANDA, S., Intervenciones genéticas sobre el ser humano y Derecho Penal, cit., pág. 365 y ss.). Pero es que, además, hay al menos cuatro interpretaciones que pueden derivarse de la redacción del precepto (Véase: RoMEO CASABONA, C. M., "Los delitos relativos a la manipulación genética”, págs. 355 y ss.; DEL MoRAL, A., “Clonación y Derecho Penal”, en PÉRez Del VAlLe, C. (Dir.), Genética y Derecho, Cuadernos de Derecho Judicial, Consejo General del Poder Judicial, Madrid, 2004, pág. 85).
} 
Sin embargo, creemos que también es posible considerar lo contrario, si la expresión "otros procedimientos” se liga inseparablemente a la selección de razas $^{8}$.

La duda más relevante que surge en este punto, no obstante, atañe a la primera parte de la definición, esto es, la que habla de la “creación” de un ser humano. Aquí la cuestión trascendental es si la transferencia nuclear llega a crear o no un "ser humano" y, caso de que la respuesta sea afirmativa, en qué momento. Caben, de hecho, dos interpretaciones diferentes. De acuerdo con la primera, sólo estaría prohibido el intento de crear un ser humano idéntico a un adulto que ya existe, esto es, un intento que incluyera la posibilidad de que la criatura llegara a nacer, lo que implicaría su transferencia a un útero, con lo que la transferencia nuclear, de por sí, no estaría penalizada, sino solo la introducción del clon en el cuerpo de una gestante ${ }^{9}$. La segunda posible interpretación, no obstante, concluiría que no es necesario un resultado de este tipo, sino que la aplicación de la técnica, de por sí, crearía siempre una persona ${ }^{10}$.

Este dilema conoce difícil respuesta, si tenemos presente que hay una profunda división de opiniones acerca del sentido de la expresión “ser humano”, así como con respecto al hecho de si esta técnica lo acaba generando inevitablemente o no o, incluso, si es necesario que llegue a producirse un nacimiento o no ${ }^{11}$. La duda, en todo caso, queda en el aire, demostrando de

\footnotetext{
${ }^{8}$ El propio RoMEO MALANDA considera que la gemelación artificial no se halla sancionada, siempre que todos los embriones producidos a través de esta técnica se transfieran a un útero al mismo tiempo (Cfr. ROMEO MALANDA, S., Intervenciones genéticas sobre el ser humano y Derecho Penal, cit., pág. 377). En el mismo sentido, Stella MARIS MARTínEZ ha escrito que "la formulación de este tipo resulta tan genérica que permite sostener que, no sólo está prohibida la clonación propiamente dicha, sino también aquella destinada a optimizar las chances de una fecundación asistida, esto es, la que denomináramos gemelación, entiendo que, no existiendo en este procedimiento manipulación genérica alguna sino imitación de un proceso reproductivo natural tal hipótesis debe excluirse radicalmente, entendiendo que la prohibición sólo alcanza a la transferencia nuclear" (Cfr. MARIS MARTínEZ, S., "Derecho a la vida vs. Derecho a una determinada calidad de vida. Reflexiones sobre la clonación humana", en Revista de Derecho y Genoma Humano, nº 18, 2003, pág. 95).

${ }^{9}$ Sustenta esta interpretación, por ejemplo: GuARDiOla GóMEZ, J. O., "Estudio jurídico internacional sobre clonación y manipulación genética”, en Lo Canyeret, $\mathrm{n}^{\circ}$ 27, mayo-junio 2002, pág. 6.

${ }^{10}$ Es la opinión mantenida por: GARCíA GonZÁLEZ, J., Límites Penales a los últimos avances de la ingeniería genética aplicada al ser humano, Edersa, Madrid, 2001, pág. 367; RoDRíGUEZ NúÑEZ, "Delitos relativos a la manipulación genética”, en Lamarca Pérez, C. (coord.), Manual de Derecho Penal. Parte Especial, Colex, Madrid, 2ª edición, 2004, pág. 93; De LA CuESTA ARZAMENDI, J. L., "Los delitos de manipulación genética en el nuevo Código Penal español de 1995”, en Revista de Derecho y Genoma Humano, n 5, 1996, pág. 69.

${ }^{11}$ En este sentido, se ha de señalar que hay algunos autores que consideran que no es imprescindible que el ser clónico llegue a nacer para dar por consumado el delito (Véase, por ejemplo, MinaHiM, M. A., Diereito Penal e Biotecnologie, Revista dos Tribunais, Sao Paulo, 2004, pág. 143). Otros, por el contrario, opinan que el delito sólo llega a consumarse si se produce el nacimiento (Cfr. ROMEO CASABONA, C. M., "Los llamados delitos relativos a la manipulación genética: ¿Derecho Penal simbólico?”, en Romeo CAsAbona, C. M. (Dir.), Genética y Derecho Penal, Comares, Bilbao-Granada, 2001, págs. 366 y 371; PÉRez MANZANo, "Manipulación Genética”, en BAJO FERnÁndeZ, M. (Dir.), Compendio de Derecho Penal. Parte Especial, Centro de Estudios Ramón Areces, Madrid, 2003, vol. I, pág. 488; MARTín URANGA, A., La protección jurídica de las innovaciones biotecnológicas, Comares, Bilbao-Granada, 2003, pág. 427; Del MorAl, A., “Clonación y Derecho penal”, en PÉrez Del VALLE, C. J. (Dir.), Genética y Derecho, Cuadernos de Derecho Judicial, Consejo General del Poder Judicial, Madrid, 2004, pág. 87; CUERDA RIEZU, A., “¿Es punible o sancionable la clonación terapéutica en España”, en A.A. V.V., Homenaje al profesor Dr. Gonzalo Rodríguez Mourullo, Thomson-Civitas, Madrid, 2005, pág. 1259.
} 
nuevo la escasa pulcritud de la norma ahora citada ${ }^{12}$. Una redacción mucho más afortunada sería, a nuestro juicio la siguiente: “2. Con la misma pena se castigará la transferencia al cuerpo de una mujer de la entidad resultante de un proceso de transferencia nuclear”. Con ello se conseguiría, en primer lugar, diferenciar entre técnica, sea la que sea, y finalidad, la clonación y, en segundo lugar, aclarar que sólo se producirá esta clonación cuando se intente crear una persona y no, por ejemplo, cuando sólo se genere la copia de un embrión mediante gemelación artificial. Claro que esta redacción excluiría del tipo la palabra “clonación” y eso es un tanto complejo de aceptar, dada la "vis atractiva” del término.

Esta discusión, con su importancia, tiene menor trascendencia ${ }^{13}$ que la que abordaremos a continuación. Como es habitualmente conocido, la cuestión de la construcción e identificación del bien jurídico protegido es absolutamente capital en lo que atañe a la teoría del delito, constituyendo, en palabras de CoBo Del RosAl - VIVES ANTÓn, el nódulo o corazón del delito, pues ofrece un criterio material decisivo en la interpretación y construcción de la teoría jurídica del delito, y de los tipos en particular ${ }^{14}$. No cabe, en suma, caracterizar un delito si antes no determinamos cuál es el bien jurídico que se desea proteger. No hay conducta antijurídica que no lesione un bien y ha de tratarse forzosamente de un bien jurídico, sin que base un daño en el sentido sociológico del término.

De forma particular, la identificación o construcción y delimitación del bien jurídico tutelado en el delito de clonación, especialmente para el análisis que ocupa nuestra atención, constituye una actividad de particular relevancia en la medida que, la elección de uno u otro [bien jurídico] trae consigo consecuencias trascendentales para la calificación de las conductas que puedan ser sometidas al correspondiente juicio de subsunción. En este sentido, resulta clave establecer si el interés jurídicamente protegido en el delito de clonación se refleja ora en un

\footnotetext{
12 Bien es cierto, no obstante, que la práctica ha venido a demostrar que la interpretación más correcta debería ser la que niega la inclusión directa de la SCNT en el supuesto. De lo contrario, tendríamos que asumir que en los últimos años se han cometido cientos de delitos contra el bien jurídico protegido por el artículo que, permanecen, sin embargo, libres de toda persecución.

${ }^{13}$ Más aún si tenemos en cuenta que la deficiente técnica legislativa reflejada en el Código Penal español, podría ser vista como peccata minuta en comparación con la muy desafortunada redacción del artículo 324 del Código Penal peruano que, del mismo modo, se incorpora con el fin de castigar el delito de clonación (o de castigar el delito de manipulación genética — puesto que no se ha incorporado otro tipo penal específicamente destinado a castigarla —, o de castigar ambos delitos — una oferta 2x1 en toda regla —, o de no castigar ninguno de ellos por la imposibilidad material de la configuración conjunta, en el mundo del ser, de todos los elementos objetivos y subjetivos del tipo de lo injusto previstos en dicho artículo —al menos si se considera que, con el término “manipulación genética”, se hace referencia a la modificación del patrimonio genético, esto es, a la manipulación genética en sentido estricto-). En efecto, dicho artículo reza de la siguiente manera: "Toda persona que haga uso de cualquier técnica de manipulación genética con la finalidad de clonar seres humanos, será reprimido con pena privativa de la libertad no menor de seis ni mayor de ocho años e inhabilitación conforme al Artículo 36, incisos 4 y $8 ”$.

${ }^{14}$ Cobo del Rosal, M.-Vives Antón, T.S., Derecho Penal, Parte General, Valencia, 1996, p. 289.
} 
bien jurídico individual, ora en uno colectivo (¿se podría pensar, incluso, que se trata de un delito pluriofensivo?). Si el bien jurídico es colectivo ¿de qué bien jurídico estamos, concretamente, hablando?, ¿cabría pensar que, en consecuencia, se trata de un delito de mera actividad y, por tanto, de peligro abstracto? Teniendo en cuenta que, desde esta perspectiva, el tipo carecería de desvalor de resultado ¿procede negar la admisibilidad de la tentativa como forma imperfecta de ejecución del delito o, por el contrario, dicha posibilidad no queda excluida ${ }^{15}$ ?

Por el contrario, si el bien jurídico es más bien uno de naturaleza individual ¿cuál sería, concretamente, dicho bien jurídico?, ¿la vida humana prenatal?, ¿la integridad personal del individuo clónico?, ¿la falta de doble dotación genética — paterna y materna—?, ¿la identidad genética del clon? ${ }^{16} \mathrm{o}$ ¿la identidad genética del ser humano clonado? Como es evidente, la cuestión no es banal, el alcance del delito se ve directamente condicionado por la elección de uno u otro bien jurídico; incluso, la titularidad del bien jurídico puede recaer sobre personas distintas (el ser humano clónico o el ser humano clonado). De otro lado, si bien se despejan las dudas sobre la admisibilidad de las formas imperfectas de ejecución (al concebirse el delito como uno de resultado material), no es menos cierto que empiezan a surgir otros dilemas tales como los relacionados con la cuestión de si el bien jurídico es disponible o si, por el contrario, no lo es (discusión que tendría sentido si consideramos que el bien jurídico es la identidad genética del individuo clonado y que, por tanto, nos lleva a reflexionar sobre la posibilidad de admitir que el consentimiento que otorga quien da permiso para que se utilice su material biológico con el fin de crear un ser humano idéntico a él puede —o podría — llegar a operar como una causa de atipicidad de la conducta).

\section{LA CUESTIÓN DEL BIEN JURÍDICO PROTEGIDO (I): LOS BIENES JURÍDICOS COLECTIVOS}

El debate sobre cuál es el bien jurídico protegido en los delitos de clonación permanece abierto en la doctrina del Derecho Penal, siendo múltiples las diferentes posturas adoptadas: desde los que consideran que existe un único bien jurídico protegido, hasta los que consideran

\footnotetext{
${ }^{15}$ Lo cual dependerá, en buena medida, del concepto de consumación que se tome como punto de partida (formal o material). Cfr. con más detalle, GIL GIL, A. et al, Curso de Derecho Penal. Parte General, Dykinson, Madrid, $2^{a}$ edición, 2015, págs. 340 y 341.

${ }^{16}$ Véase un análisis pormenorizado respecto de los problemas y admisibilidad de cada uno de estos bienes jurídicos en: Romeo MALANDA, S., Intervenciones genéticas sobre el ser humano y Derecho penal, cit., págs. 373 y ss.
} 
que son varios; desde los que apuestan por un bien individual hasta los que defienden la existencia de uno colectivo. En este trabajo partiremos de esta última clasificación. En este apartado hablaremos de estos últimos mientras que en el siguiente abordaremos el análisis de los que propugnan un bien jurídico de carácter individual.

\subsection{Exposición}

Para los que sostienen que el bien jurídico protegido en los delitos de clonación es de naturaleza colectiva, éste estaría constituido por la diversidad genética de la especie humana, pues un atentado contra ésta podría implicar un riesgo muy elevado para la supervivencia de la humanidad ${ }^{17}$ (allí radica su naturaleza colectiva). No se nos ocurre mejor descripción de estos posicionamientos que la elaborada por Sergio RomEo MALANDA quien, sin adscribirse a tales planteamientos, indica:

“[...] nos encontramos ante otro grupo de supuestos que pueden afectar igualmente a la supervivencia de la especie humana pero en un sentido más apocalíptico. No se trata ya de garantiza su integridad genética o biológica, y de este modo su identidad como especie que la diferencia biológicamente de los demás seres vivos [...] sino de asegurar su mera existencia biológica en el planeta. A este respecto podemos referirnos a [...] los riesgos derivados de la clonación reproductiva, la cual puede suponer una pérdida de la diversidad genética y con ello la imposibilidad biológica de adecuación a las nuevas circunstancias. Esto puede conducir, en última instancia, a la desaparición de la especie.

En efecto, si la reproducción asexual no es la forma predominante de reproducción en la naturaleza, habrá que preguntarse, en consecuencia, por las ventajas de la reproducción sexual. Las dos hipótesis principales sugieren dos tipos de ventajas: a) la generación continua de variabilidad genética; y b) evitar la acumulación de mutaciones deletéreas. La primera hipótesis (a) propone que la principal ventaja de la reproducción sexual consiste en que la recombinación de genes de los progenitores da lugar a la generación continua de nuevos genotipos. La variabilidad genotípica resultante facilita la adaptación de ambientes cambiantes y, aún más importante, constituye una ventaja en la defensa frente a parásitos o agentes infecciosos que mutan muy rápidamente. [...] la segunda hipótesis (b) propone que la reproducción sexual evita la acumulación de mutaciones deletéreas que pueden llevar a la extinción en linajes asexuales.

[...] En definitiva, con vistas a la protección de la integridad genética y el desarrollo evolutivo de la especie humana, lo cual tiene su razón de ser última en la evitación del empobrecimiento de su patrimonio genético y, a fin de cuentas, en la garantía de su supervivencia, está ampliamente admitida la necesidad de prohibir determinadas conductas, que pueden concretarse [...] en las siguientes: la creación artificial de individuos genéticamente iguales [...]”. 18

${ }^{17}$ MuÑoz CONDE, cit. pág. 150.

18 Cfr. Romeo Malanda, S., Intervenciones genéticas sobre el ser humano y Derecho Penal, cit., págs. 150 y 371. Véase otra descripción sobre de tales planteamientos en URRUELA MORA, A., "La clonación humana ante la reforma penal y administrativa en España”, en Revista Penal, n. ${ }^{\circ} 21-E n e r o ~ 2008$, pág. 167. 


\subsection{Crítica}

Una de las principales críticas contra esta primera propuesta tiene que ver con el tipo de delito que configuraría un bien jurídico de este tipo. Como ha señalado ROMEO MALANDA ${ }^{19}$, unas afirmaciones como las intercaladas nos llevarían a afirmar que, el ilícito material de estudio sería un delito de peligro abstracto. Aunque la doctrina dominante ha negado la posibilidad de que el bien protegido sea éste, no podemos obviar que este interés —el de proteger la diversidad genética de la especie- más bien constituiría la ratio legis ${ }^{20}$ por la cual el legislador decidió criminalizar dicha conducta ${ }^{21}$. Frente a esta crítica, hay autores que han reiterado que nos hallamos ante un delito de resultado, que sólo se perfecciona cuando se produce efectivamente la alteración del genotipo, con la consiguiente afectación del bien jurídico "integridad de la especie y su normal desarrollo", pues de otra forma, la alteración de genotipo no ostentará interés penal ${ }^{22}$

A nuestro juicio, y con independencia de la verosimilitud o no de lo que señala el profesor Romeo MALANDA, es que no se entiende muy bien cómo y en qué sentido podría o debería considerarse un bien jurídico la normal evolución del ser humano, que es lo que al parecer no puede dejarse al arbitrio de quien puede tener acceso a los genes. Nuestra estupefacción radica, en este caso, en la desmedida fe de los citados autores en la normal evolución del ser humano, concepto que parece conceder a la naturaleza de un sentido y sentimiento protector sobre nuestro destino que no resulta, a nuestro juicio, conciliable con lo que la ciencia afirma sobre los mecanismos de la evolución. Hasta donde sabemos, las teorías darwinistas se basan en la idea de que las mutaciones genéticas son absolutamente azarosas, de tal modo que es la interacción con el medio ambiente la que contribuye o no a perpetuarlas, dependiendo de si contribuyen o no a mejorar la capacidad de adaptación de la especie. No obstante, la lucha por la supervivencia no siempre resulta favorecida por este mecanismo, ya sea porque actúa demasiado lentamente o porque una variante concreta deviene letal para el grupo. Lo cierto es que la mayor parte de las especies que han poblado nuestro planeta han acabado extinguidas, lo que incluye, por supuesto, a numerosas especies de homínidos

\footnotetext{
${ }^{19}$ Romeo MALANDA, S., Intervenciones genéticas sobre el ser humano y Derecho penal, cit., pág. 371.

${ }^{20}$ Por otra parte, siguiendo la misma lógica, podemos afirmar que la intimidad y el derecho a la autodeterminación informativa, efectivamente son intereses que constituyen una ratio legis más, sin llegar a constituir éstos ningún bien jurídico-penalmente protegido. En ese sentido cfr. ROMEO MALANDA, S., Intervenciones genéticas sobre el ser humano y Derecho penal, cit., pág. 376.

${ }^{21}$ Así, Romeo CaSABona, C. M., "La clonación humana, presupuestos para una intervención jurídico penal”, en Romeo Casabona, C. M. (Ed.), Genética y Derecho penal, Previsiones en el Código Penal Español de 1995, Cátedra de Derecho y Genoma Humano-Editorial Comares, Bilbao-Granada, 2001, nota 48, pág. 152.

${ }^{22}$ Véase, por ejemplo: MoriLlas CuEVA, L., Curso de Derecho Penal Español, cit., pág. 184; GonZÁLEz CuSSAC, J.L.: Comentarios al Código Penal de 1995, cit., pág. 825; VALLE MuÑIZ, J.M., ibíd., pág. 769.
} 
inteligentes. De ahí que la idea de confiar en la normal evolución del ser humano no parece fácil de conciliar con la conceptualización habitual de lo que es un bien jurídico, ni mucho menos. Más bien al contrario, lo que podría, incluso, considerarse como un bien sería la posibilidad de apartarse de esa línea de evolución natural para controlar los cambios que se van introduciendo en nuestro genoma desde el ingenio humano y a través de mecanismos bien asentados, como el principio de precaución, que la naturaleza no tiene, desde luego, por qué cumplir.

Puede ser, desde luego, que quienes se alinean con estos planteamientos no asuman los postulados darwinistas citados. Puede que partan de alguna forma de creacionismo, o de una visión de la evolución que considera como un hecho la divina providencia. Puede ser también —aunque ello nos dejaría un tanto concernidos, cuando no desolados— que, desde una posición un tanto misántropa, lo que considerarían en realidad un bien sería dejar actuar a la evolución, depositando sus esperanzas en que ello condujera más temprano que tarde a la extinción de la especie humana. No lo parece a tenor de las explicaciones dadas, pero podría deducirse del espíritu de dicho argumento en su conjunto. Sea cual sea el caso, entendemos que esta clase de consideraciones no deberían tener demasiado pábulo en una ciencia del Derecho Penal ni en ninguna otra ciencia que aspira a liberarse de según qué tipo de anclajes colectivos que muestran, en general, poca confianza en el ser humano ${ }^{23}$. La cuestión, a nuestro juicio, no debe ser en ningún caso caer en un naturalismo extremo que ponga en duda la aceptabilidad de un comportamiento humano razonable, como la alteración de la evolución natural.

\section{LA CUESTIÓN DEL BIEN JURÍDICO PROTEGIDO (II): LA INTEGRIDAD O LA IDENTIDAD GENÉTICA DEL CLON}

\subsection{Exposición}

Frente a las corrientes que acabamos de describir, hay otra ${ }^{24}$, mayoritaria, que se decanta por considerar que el bien jurídico tutelado estaría constituido fundamentalmente por la identidad genética del clon, lo que no significa necesariamente que ambos bienes sean excluyentes. Incluso cabría pensar en otros más. Así, por ejemplo, ROMEO CASABONA ha escrito

\footnotetext{
${ }^{23}$ Hay que señalar que, en este caso, RomEO CASABONA concede que por el momento no hay razones para pensar que esta técnica pudiera poner en peligro la variabilidad genética humana, por lo que no sería razón suficiente para propugnar la intervención del Derecho Penal (Romeo CAsABona, C. M., "Bienes jurídicos implicados en la clonación”, en Revista de Derecho, Criminología y Ciencias Penales, n² 2, 2000, pág. 148).

${ }^{24}$ Cfr. Romeo CASABOna, C. M., op. cit., págs. 150-152; y RomeO MALANDA, S., Intervenciones genéticas sobre el ser humano y Derecho penal, cit., págs. 375-376.
} 
que en una primera fase se podría considerar como un bien jurídico a proteger la integridad física de los niños producidos a través de esta técnica, que al menos en su primera fase entrañaría graves riesgos y altas probabilidades de crear personas aquejadas de ciertas taras físicas ${ }^{25}$. No obstante, tanto él mismo como VALLE MUÑIz y TAMARIT SuMALLA ${ }^{26}$ consideran que más allá del riesgo que la clonación humana supone para la integridad física del individuo así creado, lo preponderante ha de ser la defensa de los intereses relativos a la identidad genética del ser obtenido mediante clonación.

Carlos María ROMEO CASABONA, de hecho, considera que la creación de seres humanos idénticos por clonación puede comportar un atentado a la identidad e irrepetibilidad genética del ser humano (como parte del derecho a la individualidad y a la condición de ser uno mismo distinto a los demás) cuando ello ha sido predeterminado deliberadamente por la acción de otro ser humano. Cierto es, no obstante, que concede que un clon no sólo viene a resultar determinado por su identidad genética, sino por otros muchos factores, lo que vendría a atenuar el presunto perjuicio a su identidad ${ }^{27}$. Ello no obstante, caben pocas dudas de que la conformación genética de cada uno es una de las bases de nuestra irrepetibilidad, siendo así que algunos autores, como JonAs, al que Romeo cita en su argumentación profusamente, han llegado, incluso, a considerarla como una condición previa para la protección del libre desarrollo de la persona ${ }^{28}$. Por su parte, y en este mismo sentido, Sergio RoMEO MALANDA, a su vez, apunta que "En definitiva, lo que se está protegiendo es la necesidad de que cada individuo tenga un genotipo propio, en el sentido que sea un genotipo originario, que no posea

\footnotetext{
${ }^{25}$ Romeo Casabona, C. M., “Bienes jurídicos implicados en la clonación”, cit., pág. 148.

${ }^{26}$ VAlle MuÑIZ, J. M. \& TAMARIT Sumalla, J. M., “Título V. Delitos relativos a la manipulación genética”, cit., págs. 169 y s.

${ }^{27}$ Vid. Romeo Casabona, C. M., “Bienes jurídicos implicados en la clonación”, cit., págs. 149 y ss.

${ }^{28}$ El principal promotor de esta idea ha sido, probablemente, Hans JoNAS, a quien se deben las siguientes palabras: "el hecho sencillo y sin precedente es que el — hipotético- clon sabe (o cree saber) demasiado de él. Ambos hechos, el propio y el supuesto saber y el de los otros, son paralizantes para la espontaneidad de su llegar a ser "él mismo”, y el segundo hecho también para la autenticidad del trato de otros con él (...) Da igual que el supuesto saber sea verdadero falso (...): es pernicioso para la obtención de la propia identidad. Porque lo esencialmente significativo es que la persona clonada piensa - tiene que pensar- que no es lo que "es" objetivamente, en el sentido sustancial del ser. En resumen: al producto de la clonación se le ha robado de antemano la libertad, que sólo puede prosperar bajo la protección de la ignorancia. Robar premeditadamente esta libertad a un futuro ser humano es un crimen inexpiable, que no debe ser cometido ni una sola vez” (Cfr. JonAs, H., Técnica, Medicina y Ética, págs. 127 y ss.). Véase también, en este mismo sentido: KAUfMANN, A., Filosofía del Derecho, Universidad Externado de Colombia, Bogotá, 1999, pág. 556; HABERMAS, J., El futuro de la naturaleza humana. ¿Hacia una eugenesia liberal?, Paidós, Barcelona, 2002, págs. 86 y ss.; GAFO, J., “El nuevo "homo habilis”, en BARBERO SANTOS, M. (Ed.)., Ingeniería genética y reproducción asistida, Madrid, 1989, pág. 168; PuigPELAT, F., “Clonación, dignidad humana y constitución”, en Revista Brasileira de Ciencias Criminais, n 42, 2003, pág. 59; Ruiz Miguel, A., “Azar, igualdad y biotecnología”, en A.A. V.V., Homenaje al Profesor Dr. Gonzalo Rodríguez Mourullo, Thomson Civitas, Madrid, 1995, pág. 2133, nota 3; VALlE MuÑIZ, J. M. y TAMARIT SumalLA, J. M., "Delitos relativos a la manipulación genética”, en Quintero Olivares, G. y R. Morales Prats (Coord.), Comentarios al Nuevo Código Penal, $3^{a}$ edición, Aranzadi, Cizur Menor, 2004, pág. 825.
} 
o haya poseído otro ser humano con anterioridad a él, pues de lo contrario se vería afectada su identidad genética” 29 .

Nos encontramos, en suma, con que los citados autores han procedido a enlazar la idea de identidad genética con la de identidad personal, extendiendo así el derecho al libre desarrollo de la personalidad, proclamado en el art. 10.1 de nuestra Carta Magna, a esta materia en concreto $^{30}$. Otros autores que podríamos adscribir en cierta medida a esta corriente son, por ejemplo, MuÑoz Conde, quien, sostiene que el bien jurídico está constituido "no solo por la individualidad e identidad genética del ser humano, sino también por todo el riesgo que ello representa para la propia humanidad”, asumiendo de esta manera la coexistencia de un bien jurídico individual y uno colectivo ${ }^{31}$, o Alfonso SERRANO GómEZ y Alfonso SERRANO MAílLO, que han manifestado que lo que se quiere proteger es más bien la identidad personal de cada individuo, la dignidad humana y la propia libertad de los individuos ${ }^{32}$.

Hay, en cualquier caso, que aclarar que el hecho de compartir un mismo ADN con otra persona no significa por sí mismo una pérdida de identidad genética. Piénsese, en este sentido, que lo que hace que una persona pueda sentirse privada de su libertad, o de su dignidad, o de cualquier otro de los bienes de los que hablábamos más arriba no es compartir un mismo ADN con otro ser humano, sino verse reflejado en él, conocer de antemano su propia historia, sentirse como la prolongación de otro, etc. Pero todos estos factores no concurren cuando uno posee el mismo ADN que un ser humano creado en el mismo momento que él. He aquí una vital importancia entre la creación de gemelos, aunque sea artificialmente, y la de clones. El clon procede de un adulto. Los gemelos surgen simultáneamente. Por eso mismo, y como confirma nuestra experiencia, no sufren de ninguna de las taras que, se supone afligirían a los clones. Y es que, si fijamos una mirada atenta sobre la cuestión, nos daremos cuenta rápidamente de que el problema real no es el de compartir un mismo ADN con otro ser humano, sino el de compartirlo con una persona que vive en un intervalo temporal diferente.

${ }^{29}$ Cfr. Romeo Malanda, S., Intervenciones genéticas sobre el ser humano y Derecho Penal, cit., págs. 375 y 376.

${ }^{30}$ A este respecto, RomEO CASABONA ha escrito que "la Constitución española, cuando proclama el libre desarrollo de la personalidad como uno de los fundamentos del orden político y de la paz social (art. 10.1), sitúa en este marco la cuestión" (Cfr: ROMEO CASABONA, C. M., "La Clonación Humana: presupuestos para una intervención jurídico-penal", en Romeo Casabona, C. M. (Ed.), Genética y Derecho Penal, Comares, Granada, 2001, pág. 139.

${ }^{31}$ Cfr. MuÑoz Conde, F., Derecho penal, Parte especial, Decimoquinta edición, Tirant lo Blach, Valencia, 2004, pág. 150.

32 Serrano Gómez, A. y Serrano Maíllo, A., Derecho penal, Parte especial, Décima edición, Dykinson, Madrid, 2005, pág. 151. 
De este modo, cobra sentido, a pesar de que, con loables excepciones ${ }^{33}$, no se haga, la distinción entre los conceptos de individualidad genética, que consiste en la posesión de un ADN único, originalidad genética, que implica la posesión de un código genético diferente al de cualquier otro ser humano nacido en un momento temporal diferente, y el de identidad genética, ya descrito como el hecho de ser uno mismo. Siguiendo esta distinción es más sencillo entender por qué creemos que la partición de embriones no atenta contra la identidad genética de los gemelos creados gracias a ella. Dado que la identidad genética, como tal, se halla relacionada con la idea de originalidad genética, pero no, en cambio, con la de individualidad genética, es obvio que la gemelación artificial no supone una amenaza contra la identidad genética, ya que lo que crea son seres genéticamente idénticos entre sí, pero dotados de ADN original, como acabamos de señalar. Hay, con todo, que hacer una salvedad a este aforismo general, que tiene que ver con la posibilidad de congelar algunos de esos embriones. En tales casos, esto es, en los casos de transferencia de embriones gemelos en intervalos temporales diferentes, tendríamos que remitirnos a lo que a continuación diremos sobre la clonación de seres humanos ya nacidos.

\subsection{Crítica}

A primera vista, las consideraciones introducidas por todos los autores citados parecen muy razonables, por cuanto la identidad genética, esto es, la posesión de un ADN original, es, como tal, un bien, esto es, algo que "es susceptible de contribuir al bienestar y perfeccionamiento físico o psíquico de la persona” ${ }^{34}$, porque es bueno que un ser humano sea único, irrepetible y diferente a otros seres vivos preexistentes, estén vivos o muertos ${ }^{35}$. Esto, desde luego, no significa que la posesión de un ADN único y la identidad genética, tal y como la hemos definido, sean lo mismo, como muchos de esos autores han subrayado, ya que es perfectamente posible que dos personas que posean un mismo ADN no se sientan por ello, en absoluto, idénticas ${ }^{36}$. No obstante, sigue siendo cierto que la posesión de una conformación genética original es algo valioso para la persona.

\footnotetext{
${ }^{33}$ En este sentido, merece especial alabanza, por su esfuerzo clarificador, el trabajo del doctor ROMEO MALANDA, quien diferencia entre identidad e individualidad genética y originalidad genética. Lo primero no es realmente esencial, lo segundo, sí (Cfr. Romeo MALANDA, S., Intervenciones genéticas sobre el ser humano y Derecho Penal, cit., págs. 155 y ss.).

34 Cfr. Polaino Navarrete, M., El bien jurídico en el Derecho Penal, Publicaciones de la Universidad de Sevilla, Sevilla, 1974, págs. 29 y ss. y Rodriguez Mourullo, G., Derecho Penal. Parte General, Civitas, Madrid, 1977, pág. 19.

${ }^{35}$ Cfr. Romeo CaSABOna, C. M., “Bienes jurídicos implicados en la clonación”, cit., pág. 148.

${ }^{36}$ Piénsese, por ejemplo, en los gemelos.
} 
Ahora bien, a pesar del ingente esfuerzo desarrollado por la doctrina con el fin de defender las consideraciones anteriormente descritas (consideraciones que, además, son hoy defendidas por la doctrina más autorizada y dominante) creemos que la argumentación con la que se respalda dicho planteamiento puede, en efecto, ser cuestionada y, por tanto, refutada, desde el prisma de la lógica — salvo, claro está, que la tesis subyacente a dicho argumento sea la de que vivir como un clon es mucho peor que no haber existido nunca y esto, de ser así, requeriría una explicación y justificación mucho más evidente, sosegada y consistentePermítasenos explicar la cuestión con cierto detalle, no tanto por el ánimo de evidenciar los problemas de coherencia lógica que presentan estos planteamientos, sino por el de contribuir a avanzar en el desarrollo de la ciencia jurídica.

Empecemos por lo más simple. Como es de sobra conocido, el Derecho Penal sólo debe intervenir cuando se dan razones más que justificadas que amparan esta intervención. En este sentido, es opinión dominante en la doctrina española, que al Derecho Penal le incumbe la “tarea de protección de los bienes vitales fundamentales del individuo y la comunidad” ${ }^{37}$, en otras palabras es función primaria de este sector del ordenamiento jurídico la protección de los bienes jurídicos. Esta afirmación determina, en cierta medida, el horizonte del Derecho Penal y ha facilitado la incorporación de múltiples principios y garantías limitadoras del poder punitivo. A efectos del análisis que ocupa nuestra atención, resultan especialmente relevantes los tres principios siguientes:

a) Principio de exclusiva protección de bienes jurídicos: El cual implica, en palabras de Boldova Pasamar, que "solo tiene sentido que se prohíban u ordenen los comportamientos en relación con la necesidad de otorgar la protección del Derecho a lo bines jurídicos esenciales $[\ldots]^{38 \%}$.

b) Principio de lesividad u ofensividad: El cual, a su vez, nos lleva a afirmar que es preciso que la conducta del autor lesione, si quiera mínimamente, al bien jurídico protegido o que, al menos, lo ponga en peligro de ser lesionado.

c) Principio de proporcionalidad: Del cual derivan, además del sub-principio de proporcionalidad en sentido estricto, los sub-principios de necesidad y de adecuación a un fin determinado (o de idoneidad). Este último sub-principio reviste un especial interés para nuestro análisis puesto que se encuentra referido al hecho de que es una exigencia del Estado de

\footnotetext{
${ }^{37}$ Cerezo Mir, J., Curso de Derecho Penal Español. Parte General. I Introducción, Tecnos, Madrid, 6ta edición, 2004, pág. 13.

${ }^{38}$ Boldova Pasamar, M. A., Los principios del Derecho Penal, en Romeo Casabona, C. M., Sola Reche, E. y Boldova Pasamar, M. A. (Coords), Derecho Penal. Parte General. Introducción. Teoría Jurídica del Delito, Comares, Granada, 2013, pág. 42.
} 
Derecho que la imposición de la consecuencia jurídica del delito no sea gratuita, sino apta (útil, idónea) para la consecución de los fines a los que se dirige. Y el fin al que se dirige la pena dispuesta para la comisión del delito de clonación, no sería otro que reprochar al autor la lesión del bien jurídico protegido (sin perjuicio de que, en consonancia con la teoría de pena asentada en nuestra doctrina, puedan coexistir, junto a esta finalidad, otras de naturaleza preventiva y de particular relevancia).

Dicho de otra forma, la intervención del Derecho Penal queda habilitada cuando, entre otras, se cumplan las dos siguientes condiciones: que la intervención sea útil e idónea para la consecución del fin propuesto (esto es, que sirva efectivamente para reprochar al autor la lesión del bien jurídico) y que sea necesaria (esto es, que no quepa otra forma de proteger el bien jurídico eficientemente). Es cierto que el valor que atribuyamos al bien jurídico será también decisivo para establecer la clase y el rigor de la pena que se ha de imponer a aquellas conductas que lo lesionen o lo pongan en peligro, pero lo fundamental, en todo caso, es el cumplimiento adicional de las dos condiciones previamente mencionadas.

En el caso de la clonación, es muy obvio que, si el bien jurídico protegido es la identidad genética del clon, entonces la intervención el Derecho Penal (y de cualquier otra rama del Derecho que pretenda proteger este bien) será injustificable, no por desproporcionada, sino por inútil. Y ello es así por un simple motivo: no cabe crear clones con identidad genética propia. Con lo que el dilema se resume, simplemente, bien en permitir que existan seres sin ese bien, o bien en impedir que existan. Pero lo que es imposible es que lleguen a este mundo con el bien jurídico que se desea proteger (presuntamente): su identidad genética (o su integridad física, si fuera el caso).

Pongamos un ejemplo: imaginemos que el científico A crea un embrión clónico (un clon) al que denominaremos B. Pues bien, ahora pensemos que desea implantarlo en el útero de una mujer, cosa prohibida por el Derecho. Supongamos que, en su ignorancia de las normas, o conociéndolas pero decidido a pasar a la historia, finalmente lo hace. En tal caso, y si todo sale bien, acabará naciendo un niño sin identidad genética propia. Luego el bien jurídico protegido no existirá. Hasta aquí, todo en orden: no se ha protegido porque el Derecho Penal no ha impedido la acción criminal, aunque habrá que aplicar la sanción. Pensemos ahora, no obstante, que A, alertado de la sanción que podría ocasionarle la transferencia, decide no llevarla a cabo. Obviamente, ya no habrá un sujeto -B- nacido sin identidad genética propia. ¿Victoria para el Derecho Penal? ¿Ha conseguido preservar un bien jurídico propio de B? Permítasenos responder a esta pregunta formulando otra: ¿dónde está B? Que sepamos, seguirá en la placa de Petri. Y eso si no lo han congelado o, directamente, tirado a la basura. Y ni 
siquiera será B, sino un embrión que podría convertirse en B. Luego, en caso de éxito del Derecho Penal, simplemente, B no existirá. Salvo que B pensara que vivir sin identidad genética propia, no parece que la enérgica defensa de sus intereses por parte del Derecho Penal le haya sido de gran ayuda. Pero, en todo caso, está claro que el bien jurídico que se deseaba preservar, esto es, la identidad (o la integridad física) de B, no se preservaría: si B no existe, las cualidades de B se resienten sobremanera.

Intentemos explicarlo, por si ayuda, de otra forma. Imaginemos ahora que A llega a crear a B y éste nace con su integridad física muy afectada por su origen. Pues bien, a juicio de los autores citados, se habría consumado un atentado contra un bien jurídico de B. Curiosamente, hay un detalle en el que no reparan: el ser humano nacido mediante transferencia de núcleos celulares difícilmente podría presentar queja alguna por sus patologías, ya que nunca hubiera nacido sin ellas. De hecho, si sus progenitores hubieran elegido otro método reproductivo, habría sido otro el embrión creado, y otro el ser humano nacido. De modo que, salvo en el caso excepcional de que las patologías que le afligieran fueran tan espantosas que le hicieran desear no haber nacido, el ser humano clónico nunca podría lamentarse de las condiciones en las que fue traído al mundo, porque nunca pudo ser engendrado en otras ${ }^{39}$. Quien, por el contrario, podría quejarse sería el ser humano preterido por sus progenitores a favor del anterior, pero, dado precisamente que nunca llegaría a existir, tampoco sería consciente de su pérdida, con lo que tampoco sufriría daño alguno ${ }^{40}$. Convendría, en este sentido, tener bien presente lo aportado al respecto por mentes tan lúcidas como Derek PARFIT ${ }^{41}$ por desgracia poco citado en el ámbito de nuestro Derecho Penal.

\footnotetext{
${ }^{39}$ Véase: HARRIs, J., Superman y la mujer maravillosa, Tecnos, Madrid, 1998, pág. 105; RoBERTSON, J. A., “The question of human cloning”, en Hastings Center Report, n 24 (2), 1994, págs. 6-14.

${ }^{40}$ En este sentido, HEYD ha escrito, con tino, que "el niño sordo potencial no tiene derecho a no nacer; ni el niño sano a nacer” (Cfr. HEYD, D., Genetics, Moral Issues in the Creation of People, University of California Press, Berkeley, 1992, págs. 109-110 y 157-158). PARFIT, por su parte, expresó ya en los años 80 del pasado siglo que "cuando afirmamos que fue bueno para alguien que se le hiciera existir, no implicamos que si no se le hubiera hecho existir eso habría sido malo para él. Y nuestras afirmaciones se aplican solamente a persona que siempre seguirán siendo meramente posibles. No estamos afirmando que sea malo para personas posibles que no lleguen a ser reales” (Cfr. PARFIT, D., Reasons \& Persons, OUP, Oxford, 1984, pág. 490). En lo que respecta a este punto, es particularmente elogiable el esfuerzo esclarecedor realizado por nuestro admirado Johh HARRIS. A dicho autor se deben las siguientes palabras: "a las personas les afecta lo que les ocurrió como prepresonas. Sin embargo, el hacer cosas a prepersonas que les impidan llegar a ser personas no se puede someter a una moralidad que afecta a las personas, salvo en la medida en que tengan efectos segundarios que afecten a las personas. Esto nos deja con una simetría abstrusa entre las obligaciones para con individuos que llegan a ser personas y obligaciones con individuos que no lo consiguen (...) He intentado mostrar que esta asimetría debe persistir hasta que de la prepersona hay surgido la persona” (Cfr. HARRIS, J., Superman y la mujer maravillosa, cit., págs. 92 y 93).

${ }^{41}$ PARFIT, D., Reasons and Persons, Oxford University Press, New York, 1984.
} 


\section{ALTERNATIVAS RAZONABLES}

La alternativa más razonable consiste en pensar que el bien jurídico protegido es la identidad genética, sí, pero no del clon, sino del ser humano clonado. Es, de hecho, curioso, que prácticamente nadie haya planteado los problemas éticos y jurídicos asociados a la clonación desde el punto de vista del ser clonado, y no desde la del clónico, cuando, en realidad, el perjuicio que nos puede causar ver nacer a una fotocopia de nosotros mismos puede ser tan grave o más que el que supone nacer siendo la copia de otra persona. ¿O es que acaso no resultaría traumático descubrir que nuestro clon es un genio del ajedrez y que nosotros nunca llegamos a desarrollar esa habilidad porque no nos enseñaron las claves de este juego-ciencia que lo contrario, esto es, que sepamos que si nos ponemos a jugar al ajedrez probablemente nos convirtamos en grandes maestros? Formulado de una manera más académica, uno podría decir que clonar atenta contra un bien jurídico fundamental del ser clonado: su originalidad genética. Pero no la del clónico o clon, claro, sino la de la persona que sí poseía esa identidad propia antes de que surgiera el clon y de la que se vio provista por su nacimiento: el clonado.

A este primer candidato a bien jurídico, habría que añadir otro, directamente relacionado con nuestra obligación de comportarnos de una forma que maximice la felicidad alcanzada con la acción. La cuestión, por tanto, sería afirmar que los progenitores deberían elegir traer al mundo hijos en las mejores condiciones posibles por un respeto a lo que podría denominarse el bien común, o el interés general, o un deber de conciencia que nos lleva a preferir que los seres que llegan a este mundo sean todo lo felices que se pueda ${ }^{42}$. Todo lo que, en principio, se suele resumir en la idea de Beneficencia Procreativa ${ }^{43}$. La base del razonamiento es, en suma,

\footnotetext{
42 En lo que a ello respecta, merece la pena citar aquí de nuevo a HARRIS, quien ha escrito que, en esta clase de casos, "la injusticia será la de traer sufrimiento evitable al mundo, la injusticia de elegir deliberadamente incrementar innecesariamente la cantidad de perjuicio o sufrimiento en el mundo, o de elegir un mundo con más sufrimiento en vez de uno con menos” (Cfr. HARRIS, J., Superman y la mujer maravillosa, cit., pág. 129. Véase también, en este mismo sentido: HARRIS, J., On cloning, Routledge, Londres, 2004, pág. 88). En sentido parecido, HEYD ha afirmado que "aunque los menores no pueden reclamar daños por haber nacido con deficiencias, una vez nacidos sus intereses han de ser satisfechos por la sociedad. Y la sociedad (...) se encuentra definitivamente en la posición de reclamar que sus intereses han sido dañados por la negligencia que condujo a la concepción del menor (...) Si los negligentes son los padres, hay razones para que la sociedad repercuta los gastos, forzándoles a arrostrar el coste de criar al niño” (Cfr. HEYD, D., Genetics, Moral Issues in the Creation of People, cit., págs. 109-110 y 157-158). Citaremos, además, a ABELLÁN, quien ha escrito que "la libertad de autodeterminación reproductiva de cualquier persona y su derecho a tomar decisiones significativas sobre su propia vida, no puede conferirlas un derecho absoluto a decidir si evitar o potenciar determinadas condiciones transmisibles genéticamente, y ello porque tales decisiones ayudan a dar forma a la naturaleza de la sociedad en la que otros van a vivir, lo que origina cierta razón para que la sociedad realice una toma de decisiones colectiva” (Cfr. ABELLAN, F., "Diagnóstico Genético Embrionario y Libertad Reproductiva en la Procreación Asistida”, en Revista de Derecho y Genoma Humano, $n^{\circ}$ 25, 2006, pág. 48 y 49). Véase también, sobre este punto: FEINBERG, J., Harm to Others, OUP, Nueva York, 1984, pág. 102.

${ }^{43}$ El principio de Beneficencia Procreativa goza de indudable raigambre histórica, hallándose ya presente, por ejemplo, en la obra de Derek PARfiT (Cfr. PARfit. D., Rights, Reasons and Persons, Clarendon Press, Oxford,
} 
sencillo: dado que un ser humano que padece graves problemas de salud será más desdichado, ceteris paribus que diría un economista, que otro que no las posee, hay una razón sólida por la que sugerir que debemos optar por un método reproductivo que implique menos riesgos de morbilidad que por otro más peligroso para el ser humano así creado.

Obviamente, alguien podría señalar que, en caso de que la procreación a través de transferencia nuclear no conociera alternativa, se podría seguir adelante sin atentar contra el bien jurídico citado. Pero con esto se estaría perdiendo la segunda parte de nuestra argumentación. Y es que hay, además, otra buena razón por la que justificar la elección preferente de métodos que crean embriones más sanos. Cuando traemos un ser humano al mundo lo hacemos presumiendo que, en caso de que nuestro hijo pudiera ser consultado, daría su consentimiento ${ }^{44}$. Esta presunción es más sólida cuanto más feliz pudiera resultar su vida. Y hay motivos racionales por los que creer que es preferible no padecer patología alguna que lo contrario. Por tanto, elegir un método proclive a crear un embrión afectado por taras graves en lugar de aquellos otros que no presentan este problema sería contrario a la lógica del consentimiento imaginado ${ }^{45}$. Y, en último término, si la patología fuera especialmente grave, hasta el punto de vista de que la vida pudiera considerarse un mal, la procreación sería un grave

1984, Part IV). Sin embargo, su formulación explícita se debe al conocido bioético australiano Julian SAVULESCU, quien acuñó la denominación en un artículo publicado en 2001 en la revista Bioethics y le dotó de una formulación precisa: las parejas (o los progenitores únicos) deberían seleccionar a sus hijos, o los posibles hijos que pudieran tener, que presumiblemente vivieran las mejores vidas, o al menos tan buenas como las de todos los demás, de acuerdo con la información relevante disponible en cada momento. Más aún, SAVULESCU argumentaba allí que este principio implicaba tanto como que las parejas deberían emplear el diagnóstico genético no sólo para detectar posibles alteraciones patológicas, sino también para hallar otro tipo de rasgos que pudieran afectar a la felicidad de las criaturas y la sociedad debería permitirles realizar estas formas de discriminación incluso si acabaran resultando en un incremento de la desigualdad social (Cfr. SAVULESCU J., "Procreative beneficence: why we should select the best children”, en Bioethics. 2001 Oct;15(5-6):413-26).

${ }^{44}$ En este sentido, PEÑA y Ausín han escrito que "cuando las circunstancias hacen totalmente dudosa la previsión de tal consentimiento, es lícito imponer la vida. No porque en tales circunstancias la vida haya de ser un mal, o sea mejor no vivir que vivir. Ni siquiera necesariamente porque, en tales circunstancias, tenga que ser preferible una situación de no vivir antes que la concreta situación de vivir así y asá (que no es lo mismo que vivir a secas, ni siquiera cuando sea imposible o humanamente irrealizable el vivir de otro modo). Sobre qué sea preferible cabe opinar. No es cierto que carezca de sentido la comparación ni que carezcamos de criterios ampliamente compartidos, aunque ni son a priori ni son estáticos ni son unánimemente aceptados” (Cfr. PEÑA, L. y T. Ausín, "Libertad de vivir", en Isegoría, nº 27, 2002, págs. 131-150). Véase también, al respecto, PeÑA, L. y T. Ausín, "Derecho a la vida y eutanasia: ¿acortar la vida o acortar la muerte”, en Anuario de Filosofía del Derecho, volumen XV, 1998, págs. 13-30.

${ }^{45}$ Esta preferencia general, en cualquier caso, y sea cual sea el motivo elegido, no se basa en que creamos que los seres que no se hallan aquejados de estas patologías son más valiosos que los que sí las padecen. La persona es valiosa por el mero hecho de ser autónoma o de ser reconocida como tal por un ser que lo es, como veremos más adelante. Esa condición, a su vez, no depende de sus características físicas o psíquicas concretas, sino del cumplimiento de la regla de reconocimiento de la propia comunidad de personas. Del hecho de que creamos que es más valioso tener dos piernas que tener una, por consiguiente, no puede extrapolarse que pensemos que una persona con una pierna es menos valiosa que la que tiene dos, por la sencilla razón de que la razón de preferencia se establece sobre las piernas, no sobre las personas. Véase al respecto: HARRIS, J., Superman y la mujer maravillosa, cit., pág. 108. 
atentado contra los intereses del ser humano afectado, que habría preferido no llegar a ser engendrado, si hubiera podido elegir esa opción.

\section{CONCLUSIONES}

De todo lo dicho a lo largo de las páginas precedentes, se pueden extraer una serie de conclusiones que hilan con el propósito fundamental de este trabajo: ofrecer una alternativa al análisis de los problemas planteados y, desde luego, alimentar el debate en relación con la interpretación del artículo 161.2 CP, así como con la política criminal y la técnica legislativa que ha sido utilizada por el legislador penal español de 1995 al regular la criminalización de la clonación humana. Quizás una de las primeras cuestiones que merece la pena recordar es, precisamente, el hecho de que el continuo e imparable avance de las biotecnologías trae consigo grandes, nuevas y prometedoras posibilidades para el cuidado y el progreso de nuestra civilización (la humana en su conjunto) pero, desde luego, también conlleva diversos riesgos que derivan del uso descuidado o, incluso, del uso malintencionado de las tecnologías que progresivamente van llegando. Tal es el caso de la clonación que, como se ha visto, podría ser aplicada a los seres humanos con fines reproductivos (de forma indiscriminada y masiva). En este sentido, parece que la voluntad del legislador penal español es tajante en relación con la prohibición del uso y aplicación de los avances en biotecnología para poder crear seres humanos idénticos (o, dicho de otro modo, para clonar seres humanos), ello se desprende de la lectura del artículo 161.2 del CP que tipifica y castiga el delito de clonación.

Como se ha visto en las páginas precedentes, la técnica legislativa utilizada para la tipificación del delito de clonación resulta, sin duda, desafortunada. Y ello por varios motivos: la redacción es sumamente farragosa, redundante, el legislador no hace un correcto uso de los términos utilizados en la redacción del tipo penal, a la luz de las distintas posibilidades ofrecidas por el avance de la biotecnología, no se establece con certeza el alcance y, por tanto, los límites del delito. En general, y como se ha intentado demostrar, todas estas deficiencias han provocado que la doctrina interprete de manera diversa el alcance y contenido del delito en cuestión. Ello, desde luego, genera una gran inseguridad jurídica.

El segundo de los aspectos analizados en este trabajo ha estado constituido por el análisis de las dos tesis más conocidas y difundidas entre la doctrina en relación con la identificación del bien jurídico que el legislador aspira a tutelar por medio del delito de clonación. No es necesario que insistamos más en la importancia que tiene la correcta construcción e identificación del bien jurídico, simplemente hemos de recordar que de él pueden depender una 
serie de factores de capital importancia, tales como el alcance del delito, el momento de la consumación, la posibilidad de admisión de las formas imperfectas de ejecución del delito, etc. En relación con ambas tesis, cabe señalar que en el presente trabajo se ha defendido que es inadmisible considerar como válida la protección de ninguno de los dos bienes jurídicos analizados. En este sentido, se ha defendido que carece de lógica el brindar protección a la “supervivencia de la especie humana” (como bien jurídico colectivo protegido) mediante, precisamente, el alejamiento del ser humano del control que puede llegar a tener sobre su propio genoma (control que nos pueda, eventualmente, permitir superar una alteración grave de nuestro entorno que, de otro modo habría sido letal para la civilización humana). En efecto, la naturaleza, a diferencia de lo que ocurre con la ciencia y la tecnología, no está (ni puede estar) orientada o programada para buscar los mecanismos más precisos para perpetuar la supervivencia de nuestra especie.

De otro lado, y en contraposición a lo defendido por la doctrina dominante, se han expuesto las razones por las que creemos que la identidad genética del clon (esto es, la posesión de un ADN original y diferente al de otros seres humanos ya nacidos) no debería poder ser concebido como el bien jurídico tutelado por el artículo 161.2 del CP. En efecto, si considerásemos que dicho bien es, e, efecto, el interés protegido por el ordenamiento jurídico, tendríamos que llegar a la conclusión de que la intervención del Derecho Penal no es, en absoluto, idónea (o, dicho de otra forma, es inútil) para la consecución de los fines que se aspiran conseguir (ello en la medida de que no es posible crear clones con identidad genética propia, es decir, es imposible que un clon llegue a este mundo dotado del bien jurídico que se desea proteger). Por último, y con el ánimo de someter a valoración de la comunidad científica una interpretación alternativa, hemos defendido que la propuesta más razonable en relación con la identificación del bien jurídico tutelado por medio del artículo 161.2 del CP, pasa por considerar que el bien jurídico protegido es la identidad genética del individuo clonado (no la identidad genética del individuo clónico). Desde luego, la propuesta defendida en este trabajo, nos lleva a plantearnos, al menos, otras interrogantes que, por sus propias características merecen un estudio individualizado y pormenorizado: ¿Puede, el bien jurídico propuesto, ser concebido como uno “disponible”? ¿qué valoración — desde la perspectiva de la teoría jurídica del delito- merecería la creación de seres humanos idénticos ante los supuestos en los que el titular dicho bien jurídico haya dado su consentimiento para el uso y replicación de su genoma? En una publicación posterior abordaremos estas cuestiones ${ }^{* *}$.

\footnotetext{
** Nos gustaría, por último, dejar constancia de nuestro agradecimiento a los miembros del equipo de investigación al que pertenecemos (G.I. Cátedra de Derecho y Genoma Humano) pues sus valiosas sugerencias, consejos y
} 


\section{REFERENCIAS}

Abellan, F., “Diagnóstico Genético Embrionario y Libertad Reproductiva en la Procreación Asistida”, en Revista de Derecho y Genoma Humano, nº 25, 2006.

Boldova Pasamar, M. A., Los principios del Derecho Penal, en Romeo Casabona, C. M., Sola Reche, E. y Boldova Pasamar, M. A. (Coords), Derecho Penal. Parte General. Introducción. Teoría Jurídica del Delito, Comares, Granada, 2013.

Cerezo Mir, J., Curso de Derecho Penal Español. Parte General. I Introducción, Tecnos, Madrid, 6ta edición, 2004.

Cobo del Rosal, M.-Vives Antón, T.S., Derecho Penal, Parte General, Valencia, 1996.

CuERDA RiezU, A., “¿Es punible o sancionable la clonación terapéutica en España”, en A.A. V.V., Homenaje al profesor Dr. Gonzalo Rodríguez Mourullo, Thomson-Civitas, Madrid, 2005.

De La Cuesta ArzAmendi, "Los llamados delitos de manipulación genética en el nuevo Código Penal español de 1995”, en Revista de Derecho y Genoma Humano, n 5, 1996.

Del Moral, A., “Clonación y Derecho Penal”, en Pérez Del Valle, C. (Dir.), Genética y Derecho, Cuadernos de Derecho Judicial, Consejo General del Poder Judicial, Madrid, 2004.

FeINBERG, J., Harm to Others, OUP, Nueva York, 1984.

FeITO GRAnde, L., "Poner en marcha la ética: elementos básicos para el análisis de la terapia génica humana”, en Revista de Derecho y Genoma Humano, nº 4, 1996.

GAFO, J., "El nuevo "homo habilis", en BARBERo SANTOS, M. (Ed.)., Ingeniería genética y reproducción asistida, Madrid, 1989.

García GonzÁlez, J., Límites Penales a los últimos avances de la ingeniería genética aplicada al ser humano, Edersa, Madrid, 2001.

GIL GiL, A. et al, Curso de Derecho Penal. Parte General, Dykinson, Madrid, 2a edición, 2015.

GonzÁlez Cussac, J. L., Comentarios al Código Penal de 1995.

reflexiones han enriquecido este trabajo. Merece la pena hacer constar algunas de sus publicaciones más recientes: EMALDI CiRIÓN, A., "Surrogacy in Spain and the proposal of a legislative change for its regulation. A global phenomenon in Europe, Revista de Derecho y Genoma Humano Genética, Ed. Dykinson, 2018, págs. 75- 99; EMALDI CiRión, A., "Derechos Constitucionales y análisis jurídico en relación con el diagnóstico genético preimplantatorio en el contexto de la reproducción asistida”, Retos del Derecho ante un Mundo Global, Ed. Tirant Lo Blanc, 2020, págs. 325-350; NicolÁs JimÉNEZ, P., “Aspectos éticos y jurídicos”, Cáncer Hereditario, $3^{\mathrm{a}}$ ed, Sociedad Española de Oncología Médica, Madrid, 2019; ATIEnZA MACÍAS, E., "Gestión democrática de la diversidad cultural: la lengua como valor identitario de las minorías lingüísticas. Reflexiones en torno a la opción canadiense por el 'acomodo razonable' de derechos”, Gestión de la diversidad cultural en las sociedades contemporáneas, Regueiro GarcíA, M. T. / PÉrez Álvarez, S. (Dirs.), Tirant lo Blanch, Valencia, 2014, págs. 589-625. 
GuARDIOLA GÓMEZ, J. O., "Estudio jurídico internacional sobre clonación y manipulación genética”, en Lo Canyeret, n⿳0 27, mayo-junio 2002.

HABERMAS, J., El futuro de la naturaleza humana. ¿Hacia una eugenesia liberal?, Paidós, Barcelona, 2002.

HARRIS, J., On cloning, Routledge, Londres, 2004.

HARRIS, J., Superman y la mujer maravillosa, Tecnos, Madrid, 1998.

Heyd, D., Genetics, Moral Issues in the Creation of People, University of California Press, Berkeley, 1992.

Jonas, H., Técnica, Medicina y Ética.

Kaufmann, A., Filosofía del Derecho, Universidad Externado de Colombia, Bogotá, 1999.

MARis MARTínEZ, S., "Derecho a la vida vs. Derecho a una determinada calidad de vida. Reflexiones sobre la clonación humana”, en Revista de Derecho y Genoma Humano, nº 18 , 2003.

MARTÍN URANGA, A., La protección jurídica de las innovaciones biotecnológicas, Comares, Bilbao-Granada, 2003.

Minahim, M. A., Diereito Penal e Biotecnologie, Revista dos Tribunais, Sao Paulo, 2004.

MinetTi, J. A. y M. J. Bertomeu, “La fundamentación de la ética biomédica”, en Jano, n 649, 1985.

Morillas Cueva, L., Curso de Derecho Penal Español.

Muñoz Conde, F., Derecho penal, Parte especial, Decimoquinta edición, Tirant lo Blach, Valencia, 2004.

PARFIT, D., Reasons and Persons, Oxford University Press, New York, 1984.

PEÑA, L. y T. Ausín, “Derecho a la vida y eutanasia: ¿acortar la vida o acortar la muerte”, en Anuario de Filosofía del Derecho, volumen XV, 1998.

PEÑA, L. y T. Ausín, “Libertad de vivir”, en Isegoría, no 27, 2002.

Pérez Manzano, “Manipulación Genética”, en Bajo Fernández, M. (Dir.), Compendio de Derecho Penal. Parte Especial, Centro de Estudios Ramón Areces, Madrid, 2003.

Polaino Navarrete, M., El bien jurídico en el Derecho Penal, Publicaciones de la Universidad de Sevilla, Sevilla, 1974.

Puigpelat, F., “Clonación, dignidad humana y constitución”, en Revista Brasileira de Ciencias Criminais, $n^{\circ}$ 42, 2003. 
Queralt Jiménez., J. J., Derecho Penal Español. Parte Especial, José María Bosch Editor, S. L., Barcelona, 1996.

Rey Del CAstillo, J., “La situación de la clonación humana en el ámbito internacional”, en Revista de Derecho y Genoma Humano / Law and the Human Genome Review, Núm. 24.

Robertson, J. A., “The question of human cloning”, en Hastings Center Report, no 24 (2), 1994.

Rodríguez Mourullo, G., Derecho Penal. Parte General, Civitas, Madrid, 1977.

RodríGuez NúÑEz, "Delitos relativos a la manipulación genética”, en LAMARCA PÉREZ, C. (coord.), Manual de Derecho Penal. Parte Especial, Colex, Madrid, 2ª edición, 2004.

Romeo Casabona, C. M., "Bienes jurídicos implicados en la clonación”, en Revista de Derecho, Criminología y Ciencias Penales, $n^{0}$ 2, 2000.

Romeo Casabona, C. M., "Bioderecho y Bioética”, en Romeo Casabona, C. M. (Dir.), Enciclopedia de Bioderecho y Bioética, Tomo I, Comares, Granada, 2011.

Romeo CASABONA, C. M., "La clonación humana, presupuestos para una intervención jurídico penal”, en Romeo Casabona, C. M. (Ed.), Genética y Derecho penal, Previsiones en el Código Penal Español de 1995, Cátedra de Derecho y Genoma Humano-Editorial Comares, Bilbao-Granada, 2001.

Romeo Casabona, C. M., "La relación entre la Bioética y el Derecho”, en Romeo Casabona, C. M. (Coord.), Derecho Biomédico y Bioética, Comares, Colección Biblioteca Comares de Derecho y Ciencias de la Vida, nº 1, Granada, 1998.

Romeo Casabona, C. M., "Los llamados delitos relativos a la manipulación genética: ¿Derecho Penal simbólico?”, en Romeo Casabona, C. M. (Dir.), Genética y Derecho Penal, Comares, Bilbao-Granada, 2001.

Romeo Malanda, S., Intervenciones genéticas sobre el ser humano y Derecho Penal, Cátedra Interuniversitaria de Derecho y Genoma Humano - Editorial Comares, Granada, 2007.

Ruiz Miguel, A., “Azar, igualdad y biotecnología”, en A.A. V.V., Homenaje al Profesor Dr. Gonzalo Rodríguez Mourullo, Thomson Civitas, Madrid, 1995.

SAVUlescu J., "Procreative beneficence: why we should select the best children”, en Bioethics, 2001.

Serrano Gómez, A. y Serrano Maíllo, A., Derecho penal, Parte especial, Décima edición, Dykinson, Madrid, 2005.

URruela MorA, A., “La clonación humana ante la reforma penal y administrativa en España”, en Revista Penal, n. ${ }^{\circ}$ 21-Enero 2008. 
Revista da Faculdade Mineira de Direito | V.23 N.46 |

Dossiê "O Direito e a Bioética ante os limites da Vida Humana em Carlos María Romeo Casabona"

VAlle Muñiz, J. M. y Tamarit Sumalla, J. M., "Delitos relativos a la manipulación genética”, en Quintero Olivares, G. y R. Morales Prats (Coord.), Comentarios al Nuevo Código Penal, $3^{a}$ edición, Aranzadi, Cizur Menor, 2004.

Submissão em 23/11/2020 / Aceito em 05/12/2020 